\title{
Quantitative Sonographic Assessment of Quadriceps Muscle Thickness for Prospective Fall Injury in Patients Undergoing Maintenance Hemodialysis: an Observational Cohort Study
}

\section{Asuka Sai}

Kodaira Kitaguchi Clinic

Kentaro Tanaka

Higashikurume Ekimae Clinic

Yasushi Ohashi ( $\nabla$ ohashiy@med.toho-u.ac.jp )

Toho University School of Medicine https://orcid.org/0000-0003-1670-9498

Akifumi Kushiyama

Meiji Pharmaceutical University

Yoshihide Tanaka

Kumegawa Tousekinaika Clinic

\section{Shuta Motonishi}

Higashiyamato Nangai Clinic

\section{Ken Sakai}

Toho University School of Medicine

\section{Shigeko Hara}

Okinaka Memorial Institute for Medical Research, Toranomon Hospital

\section{Takashi Ozawa}

Kodaira Kitaguchi Clinic

\section{Research article}

Keywords: Injury, Falls, Hemodialysis, Quadriceps thickness, Sarcopenia, Ultrasonography

Posted Date: October 6th, 2020

DOl: https://doi.org/10.21203/rs.3.rs-52610/v1

License: (c) (1) This work is licensed under a Creative Commons Attribution 4.0 International License. Read Full License 


\section{Abstract}

Introduction: Accidental fall risk is high in patients undergoing maintenance hemodialysis. Falls are associated with fatal injury, comorbidities, and mortality. Risk assessment should be conducted as a primary intervention to prevent falls. This study investigated whether quadriceps muscle thickness measured using ultrasonography can prospectively predict fall injury among dialysis patients.

Methods: Using an observational cohort study design, 180 ambulatory hemodialysis patients during the period 2015-2016 were recruited in the four dialysis clinics. The sum of the maximum quadriceps muscle thickness on both sides and the average of the maximum thigh circumference and handgrip strength after hemodialysis were calculated. Patients were stratified according to tertiles of quadriceps muscle thickness. Fall injury was surveyed according to the patient's self-report for the one-year period.

Results: Among the 180 hemodialysis patients, 42 (23.3\%) had fall injury during the 12-month follow-up period. When the quadriceps muscle thickness levels were stratified into sex-specific tertile, patients in the lowest tertile (men $<3.66 \mathrm{~cm}$ and women $<3.50 \mathrm{~cm}$ ) were more likely to have higher incidence of fall injury compared with those in the higher two tertiles ( 0.56 vs. 0.18 and 0.15 fall injuries/person-year). After adjusting for covariates, lower quadriceps muscle thickness was found to be an independent predictor for fall injury (hazard ratio [95\% confidence interval], 2.99 [1.46-6.32], $P<0.001$ ). Conversely, no significant differences were found in the thigh circumference and handgrip strength between women with fall injury and those women without fall injury.

Conclusions: Quadriceps muscle thickness using ultrasonography can be measured easily at the bedside and is a precise predictor of fall injury in patients undergoing maintenance hemodialysis.

\section{Introduction}

Aging is rapidly advancing in Japan. According to the statistical survey by the Japanese Society for Dialysis Therapy at the end of 2016, the mean age of patients on dialysis is 67.2 years old ${ }^{1}$. This trend continues from now on, which would rise an incidence of fall injury. Falls as a cause of fractures, once it occurred, may relate to the deterioration of the physical condition in elderly patients. Fall accidents occur in approximately $25 \%$ of maintenance hemodialysis patients each year ${ }^{2}$. About $20-30 \%$ of these suffer from mild to severe injury, while more than half would lead to hospitalization with high cost to the health system. Therefore, the establishment of risk assessment for falls and the countermeasures are urgent issues, with risk assessment as the primary intervention to prevent falls.

Sarcopenia, characterized by age-related decrease of the skeletal muscle mass and muscle strength and low physical performance, is a recognized geriatric syndrome in elder care during the last decade. A common consensus of sarcopenia is published by the European Working Group on Sarcopenia in Older People (EWGSOP) in $2010^{3}$ and by the Asian Working Group for Sarcopenia (AWGS) in $2014^{4}$. Sarcopenia increases the risks for adverse health outcomes such as falls, physical disability, hospital admission, 
poor quality of life, and mortality risk ${ }^{5,6}$. In fact, hemodialysis patients have high risks for falls not only because of aging but also because of unstable hemodynamic status, or some comorbidities, since falls are associated with increased mortality risk among these patients ${ }^{7,8}$. The EWGSOP recommends that the muscle mass should be measured using computed tomography (CT) scan and magnetic resonance imaging (MRI) as the gold standard. However, it is costly, and most hemodialysis clinics cannot provide such medical facilities ${ }^{2}$. Conversely, ultrasonography is widely available, noninvasive, and easily applicable at the bedside for quantitative assessment of the skeletal muscle. The measurement of quadriceps muscle thickness using ultrasonography may be useful for muscle mass assessment, which may help predict future fall injury.

This study aimed to investigate the validity of measuring quadriceps muscle thickness using ultrasonography noninvasively and the association of quadriceps muscle thickness with future fall injury among maintenance hemodialysis patients.

\section{Methods}

\section{Participants and study design}

The subjects were sampled from 732 enrolled patients with end-stage renal disease (ESRD) undergoing hemodialysis at the four dialysis clinics in April 2015. Written informed consent was obtained from 182 patients. Patients with unstable condition such as hospitalization, initiation of oral steroid administration, or lower limb amputation were excluded; participants were able to walk on their own feet at least. Finally, a total of 180 patients (127 men and 53 women; median age [(interquartile range], 69 [63-76] years old; and median duration of dialysis [(interquartile range], 5.5 [2.4-9.7] years) were included in the study. Using a prospective cohort study design, the frequency of fall injury were recorded within a follow-up period of 12 months from April 2015 to March 2016, based on the patient's self-report (median, 12 months [10th-90th percentile, 4-12 months]). A fall was defined as an event in which a person was inadvertently located on the ground or other low position. Fall injury was also defined as any injury associated with a fall including bone fracture, crack, bleeding, bruise, and abrasion.

The subject characteristics and parameters were examined: age, gender, anthropometric measures, underlying renal disease, intact parathyroid hormone, and serum albumin, lipid profile, uric acid, c-reactive protein, blood urea nitrogen, creatinine, calcium, phosphorus, $\beta 2$ microglobin, and hemoglobin levels. Blood test was performed at the start of dialysis during the first day of the week. Dialysis adequacy assessed in terms of urea reduction ratio and $\mathrm{Kt} / \mathrm{V}$ was measured using the Shinzato formula ${ }^{9}$. This study was approved by an Institutional Ethics Committee of Toyu Medical School, Tokyo, Japan (No.2014-7).

\section{Measurements of quadriceps muscle thickness, thigh circumference, and handgrip strength}


The sum of the maximum quadriceps muscle thickness on both sides, the average of the maximum thigh circumference on both sides, and the handgrip strength on both sides were measured with a grip measuring apparatus before hemodialysis. Two trials were tested on each side, and the maximum value was adopted among them. The quadriceps muscle thickness which consists of the rectus femoris and the vastus intermedius muscle was measured in the axial view at the midpoint between the anterior superior iliac spine and the lateral epicondyle of the femur. Using a B-mode ultrasound apparatus (LOGIQ BOOK XP; GE Healthcare Japan, Tokyo, Japan) with a linear scanner, the procedure was conducted by a single examiner to patients in supine position after dialysis (Fig. 1). The relative reliability of quadriceps muscle thickness by ultrasonography measurement was confirmed using intraclass correlation coefficient (ICC): right quadriceps muscle thickness ICC $(1,2)=0.99$ and left quadriceps muscle thickness $\operatorname{ICC}(1,2)=0.98$.

\section{Statistical analysis}

All data was expressed as the median and range. The differences between the two groups were assessed using the Mann-Whitney $U$ test and Fisher's exact test. The differences among the three groups were also assessed using a one-way analysis of variance. To investigate the relationship between the quadriceps muscle thickness levels and the first onset of fall injury, the quadriceps muscle thickness levels were stratified into tertiles, which were measured separately for men (the lowest tertile: $<3.66 \mathrm{~cm}$; the middle tertile:3.66-4.59 cm; the highest tertile: $\geq 4.60 \mathrm{~cm}$ ) and women (the lowest tertile: $<3.50 \mathrm{~cm}$; the middle tertile:3.50-4.49 cm; the highest tertile: $\geq 4.50 \mathrm{~cm}$ ), because the quadriceps muscle thickness levels in women tend to be lower than those in men. Fall injury as the primary outcome was analyzed using the Kaplan-Meier method, and the significance was calculated using the log-rank test. The Cox proportional hazard models were performed with fall injury and patient-related risk factors, such as the quadriceps muscle thickness levels, age (1 year of age), gender (men vs. women), dialysis vintage (1 year

of age), body mass index $\left(\mathrm{cm} / \mathrm{m}^{2}\right)$, diabetes (presence vs. absence), stroke (presence vs. absence), serum albumin $(\mathrm{g} / \mathrm{dl})$, and Kt/Vurea. Receiver operating characteristic curve analysis was used to identify the best prognostic factor for fall injury. These results are expressed as hazard ratio with $95 \%$ confidence intervals $(\mathrm{Cl})$. $P$-values $<0.05$ were considered to be statistically significant differences. All data was analyzed using JMP software (version13.0; SAS Institute Cary, NC, USA).

\section{Results}

\section{Population characteristics stratified by tertiles of quadriceps muscle thickness}

The baseline clinical and biochemical characteristics of the quadriceps muscle thickness tertiles are shown in Table 1. The lowest quadriceps muscle thickness tertile was significantly older than the higher two tertiles. Moreover, these patients were more likely to have lower body mass index (BMI) and serum albumin, triglyceride, uric acid, serum creatinine, and serum phosphate levels than those in the higher two 
tertiles. The thigh circumference and handgrip strength significantly declined in the lowest quadriceps muscle thickness tertile. 
Table 1

The baseline characteristics of the subjects stratified by tertiles of quadriceps muscle thickness

\begin{tabular}{|c|c|c|c|c|}
\hline \multirow{3}{*}{$\begin{array}{l}\text { Sample } \\
\text { characteristics* }\end{array}$} & \multicolumn{3}{|c|}{ Quadriceps muscle thickness measured using ultrasonography } & \multirow{3}{*}{$\begin{array}{l}P \\
\text { value }\end{array}$} \\
\hline & Tertile 1 & Tertile 2 & Tertile 3 & \\
\hline & $\begin{array}{l}(<3.66 \mathrm{~cm} \text { in men } \\
\text { and }<3.50 \mathrm{~cm} \text { in } \\
\text { women) }\end{array}$ & $\begin{array}{l}(3.66-4.59 \mathrm{~cm} \text { in men } \\
\text { and } 3.50-4.49 \mathrm{~cm} \text { in } \\
\text { women) }\end{array}$ & $\begin{array}{l}(\geq 4.60 \mathrm{~cm} \text { in men } \\
\text { and } \geq 4.50 \mathrm{~cm} \text { in } \\
\text { women) }\end{array}$ & \\
\hline Age (years) & $74(49-92)$ & $67(47-86)$ & $65.5(34-89)$ & $<0.001$ \\
\hline $\begin{array}{l}\text { Gender, } \\
\text { men/women }\end{array}$ & $42 / 18$ & $43 / 17$ & $42 / 18$ & 0.97 \\
\hline $\begin{array}{l}\text { Duration of } \\
\text { dialysis (years) }\end{array}$ & $5.1(0.4-33.2)$ & $5.4(0.3-31.2)$ & $6.3(0.3-28.3)$ & 0.47 \\
\hline $\begin{array}{l}\text { Body mass } \\
\text { index }\left(\mathrm{kg} / \mathrm{m}^{2}\right)\end{array}$ & $19.8(11.8-26.8)$ & $20.8(15.4-30.9)$ & $24.9(16.4-35.6)$ & $<0.001$ \\
\hline \multicolumn{5}{|l|}{ Comorbids } \\
\hline $\begin{array}{l}\text { Diabetes } \\
\text { Mellitus, } \mathrm{n}(\%)\end{array}$ & $30(50)$ & $32(53)$ & $29(48)$ & 0.86 \\
\hline Stroke, n (\%) & $11(18)$ & $13(22)$ & $10(17)$ & 0.78 \\
\hline $\begin{array}{l}\text { Ischemic heart } \\
\text { disease, n (\%) }\end{array}$ & $20(33)$ & $25(42)$ & $22(37)$ & 0.64 \\
\hline $\begin{array}{l}\text { Serum albumin } \\
(\mathrm{g} / \mathrm{dl})\end{array}$ & $3.7(3.1-4.1)$ & $3.7(3.1-4.4)$ & $3.8(3.2-4.7)$ & 0.012 \\
\hline $\begin{array}{l}\text { HDL- } \\
\text { cholesterol } \\
(\mathrm{mg} / \mathrm{dl})\end{array}$ & $43(23-87)$ & $41(25-76)$ & $40(4-91)$ & 0.30 \\
\hline $\begin{array}{l}\text { LDL-cholesterol } \\
(\mathrm{mg} / \mathrm{dl})\end{array}$ & 77 (35-139) & $81(35-154)$ & $79(23-148)$ & 0.69 \\
\hline $\begin{array}{l}\text { Triglyceride } \\
\text { (mg/dl) }\end{array}$ & $71(25-508)$ & $92(33-460)$ & $106(32-488)$ & 0.009 \\
\hline $\begin{array}{l}\text { Uric acid } \\
(\mathrm{mg} / \mathrm{dl})\end{array}$ & $6.3(3-11.1)$ & $7.0(4.1-11.9)$ & $7.3(4.5-11.1)$ & 0.002 \\
\hline $\mathrm{CRP}(\mathrm{mg} / \mathrm{dl})$ & $0.09(0.05-2.89)$ & $0.11(0.05-3.65)$ & $0.13(0.05-7.56)$ & 0.90 \\
\hline BUN (mg/dl) & $63(36-87)$ & $64(34-107)$ & $65(37-95)$ & 0.27 \\
\hline
\end{tabular}

Abbreviations: HDL, high-density lipoprotein; LDL, low-density lipoprotein; CRP, C-reactive protein; BUN, blood urea nitrogen; PTH, parathyroid hormone

*Data are expressed as median (range) or number (percentage) 


\begin{tabular}{|c|c|c|c|c|}
\hline \multirow{3}{*}{$\begin{array}{l}\text { Sample } \\
\text { characteristics* }\end{array}$} & \multicolumn{3}{|c|}{ Quadriceps muscle thickness measured using ultrasonography } & \multirow{3}{*}{$\begin{array}{l}P \\
\text { value }\end{array}$} \\
\hline & Tertile 1 & Tertile 2 & Tertile 3 & \\
\hline & $\begin{array}{l}(<3.66 \mathrm{~cm} \text { in men } \\
\text { and }<3.50 \mathrm{~cm} \text { in } \\
\text { women) }\end{array}$ & $\begin{array}{l}(3.66-4.59 \mathrm{~cm} \text { in men } \\
\text { and } 3.50-4.49 \mathrm{~cm} \text { in } \\
\text { women) }\end{array}$ & $\begin{array}{l}(\geq 4.60 \mathrm{~cm} \text { in men } \\
\text { and } \geq 4.50 \mathrm{~cm} \text { in } \\
\text { women) }\end{array}$ & \\
\hline $\begin{array}{l}\text { Creatinine } \\
(\mathrm{mg} / \mathrm{dl})\end{array}$ & $9.2(2.4-13.4)$ & $10.8(5.9-15.8)$ & $12.4(6.8-18.2)$ & $\begin{array}{l}<.001 \\
0.001\end{array}$ \\
\hline Kt/Vurea & $1.45(0.97-2.02)$ & $1.44(1.07-2.07)$ & $1.43(0.67-2.29)$ & 0.36 \\
\hline $\mathrm{Ca}(\mathrm{mg} / \mathrm{dl})$ & $8.7(6.7-11.1)$ & $8.6(7.5-10.0)$ & $8.9(6.9-10.2)$ & 0.17 \\
\hline$P(m g / d l)$ & $5.1(1.9-8.7)$ & $5.6(3.1-9.3)$ & $5.5(3.1-7.2)$ & 0.007 \\
\hline $\begin{array}{l}\text { intact PTH } \\
(\mathrm{pg} / \mathrm{ml})\end{array}$ & $136(80-200)$ & $150(76-235)$ & $128(71-183)$ & 0.35 \\
\hline $\begin{array}{l}\beta_{2} \text { microglobin } \\
(\mathrm{mg} / \mathrm{l})\end{array}$ & $25.4(9.4-39.1)$ & $27.4(11.4-35.9)$ & $26.7(12.4-46.2)$ & 0.37 \\
\hline $\begin{array}{l}\text { Hemoglobin } \\
(\mathrm{g} / \mathrm{dl})\end{array}$ & $10.9(7.9-13.3)$ & $10.7(9.2-13.2)$ & $10.8(9.3-13.4)$ & 0.52 \\
\hline $\begin{array}{l}\text { Thigh } \\
\text { circumference } \\
\text { (cm) }\end{array}$ & $39(36-42)$ & $42(39-45)$ & $46(44-50)$ & $\dot{0.001}$ \\
\hline $\begin{array}{l}\text { Handgrip } \\
\text { strength (kg) }\end{array}$ & $20.7(6.4-35.7)$ & $23.9(12.8-42.8)$ & $25.2(11.1-49.4)$ & $\begin{array}{l}<.001 \\
0.001\end{array}$ \\
\hline
\end{tabular}

Abbreviations: HDL, high-density lipoprotein; LDL, low-density lipoprotein; CRP, C-reactive protein; BUN, blood urea nitrogen; PTH, parathyroid hormone

*Data are expressed as median (range) or number (percentage)

\section{Associations of quadriceps muscle thickness, thigh circumference, and handgrip strength with fall injury}

During a 12-month follow-up period, 42 (23.3\%) out of 180 patients had fall injury. As shown in Fig. 2, men with fall injury were more likely to have lower quadriceps muscle thickness, thigh circumference, and handgrip strength than those men without fall injury. Women with fall injury were also more likely to have lower quadriceps muscle thickness than those women without fall injury. Thigh circumference and handgrip strength tend to have lower values in women with fall injury compared to those women without fall injury. However, no significant differences were observed among these values.

Patients in the lowest tertile had a significant higher risk of fall injury than those in the higher two tertiles (log-rank test, $P<0.001$ ) (Fig. 3). The lowest tertile had 24 events, an incidence of 0.57 fall injury/personyear, and a cumulative incidence of $40.0 \%$. Otherwise, the middle tertile and the highest tertile had almost the same frequency of fall injury but were less than those in the lowest tertile. The middle tertile 
developed 10 events (an incidence of 0.18 fall injury/person-years, $16.6 \%$ cumulative incidence), and the highest tertile developed 8 events (an incidence of 0.15 fall injury/person-years, $13.3 \%$ cumulative incidence).

In univariate analysis, the lowest quadriceps muscle thickness tertile, diabetes, and serum albumin level were associated with a higher risk of fall injury (Table 2). In multivariate analysis, the lowest quadriceps muscle thickness tertile still remained significant after various confounding factors such as age, gender, dialysis vintage, BMI, diabetes, stroke, KT/Vurea, and serum albumin level have been adjusted (hazard ratio [95\% Cl], 2.99 [1.46-6.32], $P<0.001)$. If thigh circumference and handgrip strength were used as one of the dependent variables, the independency of quadriceps muscle thickness remained similar (data not shown). Then, the receiver operating characteristic curves were constructed to determine the cutoff of quadriceps muscle thickness that best predicts fall injury. The optimal cutoff values for men and women were $3.66 \mathrm{~cm}$ and $3.54 \mathrm{~cm}$, respectively. Using these cutoff values, the respective areas under the curve were $0.620(95 \% \mathrm{Cl}, 0.509-0.739)$ and $0.774(95 \% \mathrm{Cl}, 0.617-0.904)$.

Table 2

Independent risk factors associated with fall injury

\begin{tabular}{|c|c|c|c|c|}
\hline \multirow[t]{2}{*}{ Variables } & \multicolumn{2}{|l|}{ Univariate analysis } & \multicolumn{2}{|c|}{ Multivariate analysis ${ }^{*}$} \\
\hline & $\mathrm{HR}(95 \% \mathrm{Cl})$ & P-value & $\mathrm{HR}(95 \% \mathrm{Cl})$ & $P$-value \\
\hline The lowest QT tertile & $3.37(1.83-6.31)$ & $<0.001$ & $2.99(1.46-6.32)$ & $<0.001$ \\
\hline Age, 1 year of age & $1.02(0.99-1.04)$ & 0.22 & $1.00(0.97-1.03)$ & 0.93 \\
\hline Men gender & $0.76(0.41-1.46)$ & 0.41 & $0.62(0.31-1.28)$ & 0.19 \\
\hline Duration of dialysis, every 1 year & $1.02(0.97-1.05)$ & 0.41 & $1.08(1.01-1.14)$ & 0.012 \\
\hline Body mass index & $0.94(0.86-1.01)$ & 0.11 & $0.95(0.85-1.05)$ & 0.29 \\
\hline Diabetes Mellitus & $3.14(1.63-6.54)$ & $<0.001$ & $3.97(1.85-9.34)$ & $<0.001$ \\
\hline Stroke & $1.76(0.86-3.34)$ & 0.12 & $1.85(0.89-3.61)$ & 0.10 \\
\hline Serum albumin & $0.20(0.06-0.66)$ & 0.007 & $0.35(0.10-1.22)$ & 0.10 \\
\hline Kt/Vurea & $0.68(0.18-2.51)$ & 0.57 & $0.29(0.05-1.85)$ & 0.10 \\
\hline \multicolumn{5}{|c|}{ Abbreviations: HR, hazard ratio; QT, quadriceps muscle thickness } \\
\hline
\end{tabular}

\section{Discussion}

In this cohort study, any fall accidents were observed in 42 (23.3\%) maintenance dialysis patients for a one-year period. The quadriceps muscle thickness measured using ultrasonography was significantly 
associated with future fall injury, with the optimal cutoff values of $3.66 \mathrm{~cm}$ and $3.54 \mathrm{~cm}$ for men and women, respectively. Particularly, quadriceps muscle thickness may be more precise predictor for fall injury than the thigh circumference and handgrip strength in women dialysis patients.

Falls tend to occur in elderly people and are observed in dialysis patients with high frequency. Fall injury often lead to hospitalizations, starting the downward spiral of physical disorder that can result in longterm functional disability or death. Muscle weakness and frailty were considered the most important risk factor of falls $s^{4,10}$. Sarcopenia occurred more frequently in hemodialysis patients ${ }^{5,11}$. The EWGSOP gave us a common consensus about muscle mass assessment for aging. The CT scan and MRI which would be the gold standard in measuring skeletal muscle mass more precisely are widely used. On the other hand, these techniques have numerous problems including costs, limited number of facilities, time consumption, and radiation exposure, so that most dialysis units cannot carry them out routinely for a large number of subjects in general practice. Alternatively, dual-energy X-ray absorptiometry (DEXA) and bioelectrical impedance spectroscopy (BIA) are simpler inspection methods. However, DEXA remains to be problematic regarding radiation exposure and inspection equipment. Portable BIA may have calculation errors because excess fluid is miscalculated as muscle mass ${ }^{12}$.

Recently, some studies reported about the reliability of bedside ultrasound for the measurement of muscle thickness ${ }^{13-16}$. Muscle thickness measured using a sonographic technique has a high correlation with the CT scan and MRI values ${ }^{17}$. Sabatino $A$ et al. reported the significant decrease of quadriceps femoris muscle in hemodialysis patients compared to healthy adults ${ }^{18}$. In this study, the quadriceps muscle thickness was comparable to the result of the previous study. More importantly, the quadriceps muscle thickness measured using ultrasonography was clinically verified as an independent risk factor for fall injury.

Many risk factors have been proposed for the development of fall injury in hemodialysis patients: age, diabetes, handgrip strength, antidepressant agents, and sarcopenia ${ }^{19,20}$. The association of diabetes for fall injury have already been investigated by several researchers ${ }^{21,22}$. Diabetes patients are prone to fall due to its complications such as hypoesthesia from peripheral neuropathy, loss of vision from retinopathy, orthostatic hypotension from autonomic disturbance, and hypoglycemia. In this study, diabetes is also associated with fall injury similar to those of previous studies.

Low handgrip strength can possibly cause falls or activities of daily living disability ${ }^{23}$. The handgrip strength is known to correlate with the limb muscle strength, which is available for the evaluation of muscle strength ${ }^{24}$. In this study, handgrip strength was correlated with quadriceps muscle thickness. However, median handgrip strength in women with fall injury and those women without fall injury was $16 \mathrm{~kg}$ and $18 \mathrm{~kg}$, respectively. The difference was insignificant and hardly distinguishable. Muscle strength may not always depend on muscle mass; a study showed the association between muscle strength and muscle mass is not a straight line ${ }^{25}$. Additionally, the association of thigh circumference 
with fall injury as even easier parameter was investigated. However, the relationship was lesser in women because thigh circumference may include the other component except muscle mass.

Previous studies have confirmed that sarcopenia can lead to falls, disability, hospital admission, longterm care placement, poorer quality of life, and increased mortality rate ${ }^{24,26}$. Sarcopenia patients were over three times more likely to fall relative to non-sarcopenia patients ${ }^{27}$. Japan is one of the most rapidly aging countries in the world. Moreover, hemodialysis patients are generally considered as a high-risk group for sarcopenia due to inflammation, malnutrition by dietary therapy, loss of protein from dialysis membrane, low performance by complications or comorbidity, and time loss by dialysis schedules ${ }^{28,29}$. Mainly, this study aimed to assess the risk of falls affecting the prognosis of hemodialysis patients, since muscle thickness measured using ultrasonography has been confirmed to easily and accurately evaluate the risk of future fall injury.

This study had several limitations. First is the relatively few subjects enrolled in this study. The optimal cutoff values are just for reference. Second, the results were not compared with an observation of the muscle mass using CT or MRI. Third, this study did not discuss the following issues: how to improve physical performance, quality of life, and mortality from rehabilitation or nutrition management perspectives. Hence, further study is necessary considering methods of recuperation including the abovementioned issues comprehensively.

\section{Conclusions}

Quadriceps muscle thickness using ultrasonography can be easily measured at the bedside and is a precise predictor of fall injury in patients undergoing maintenance hemodialysis. Thus, from now on, quantitative sonographic assessment of quadriceps muscle thickness is worth considering from a prognostic point of view.

\section{Abbreviations}

\section{EWGSOP}

European Working Group on Sarcopenia in Older People; AWGS:Asian Working Group for Sarcopenia; $\mathrm{CT}$ :computed tomography; MRI:magnetic resonance imaging; ESRD:end-stage renal disease; ICC:intraclass correlation coefficient; BMI:body mass index; DEXA:dual-energy X-ray absorptiometry; BIA:bioelectrical impedance spectroscopy

\section{Declarations}

\section{Ethics approval and consent to participate}

This study was approved by an Institutional Ethics Committee of Toyu Medical School, Tokyo, Japan (No.2014-7) and was performed in adherence with the Declaration of Helsinki. Informed written consent was obtained from patients prior to data collection. 


\section{Consent for publication}

Not applicable

\section{Availability of data and materials}

The datasets used and/or analysed during the current study are available from the corresponding author on reasonable request.

\section{Competing interests}

The authors declare that they have no conflicts of interest concerning this article.

\section{Funding}

This study received no specific funding.

\section{Authors' contributions}

Substantial contribution to conception and design (OT), acquisition of data (SA, TK and MS), or analysis (TK and OY) and interpretation of data (KA, HS and OY). Drafting the article (SA and OY) or revising it critically for important intellectual content (TY and SK). Final approval of the version to be published (all authors). Agreement to be accountable for all aspects of the work thereby ensuring that questions related to the accuracy or integrity of any part of the work are appropriately investigated and resolved (all authors).

\section{Acknowledgements}

The authors thank Yui Izumi, Nao Okumura, and Yukiko Uchiyama for conducting the physical performance evaluation of the patients.

\section{References}

1. Masakane I, Nakai S, Ogata S, Kimata N, Hanafusa N, Hamano T, et al. An overview of regular dialysis treatment in Japan (As of 31 December 2013). Ther Apher Dial. 2015;19:540-74.

2. Kutner NG, Zhang R, Huang Y, Wasse $\mathrm{H}$. Falls among hemodialysis patients: potential opportunities for prevention? Clin Kidney J. 2014;7:257-63.

3. Cruz-Jentoft AJ, Baeyens JP, Bauer JM, Boirie Y, Cederholm T, Landi F, et al, European Working Group on Sarcopenia in Older People. Sarcopenia: European Consensus on Definition and Diagnosis: Report of the European Working Group on Sarcopenia in Older People. Age Ageing. 2010;39:412-23.

4. Chen LK, Liu LK, Woo J, Assantachai P, Auyeung TW, Bahyah KS, et al. Sarcopenia in Asia: consensus report of the asian working group for sarcopenia. J Am Med Dir Assoc. 2014;15:95-101.

5. Woo J. Sarcopenia. Clin Geriatr Med. 2017;33:305-14. 
6. Moorthi RN, Avin KG. Clinical relevance of sarcopenia in chronic kidney disease. Curr Opin Nephrol Hypertens. 2017;2 6:219-28.

7. Polinder-Bos HA, Emmelot-Vonk MH, Gansevoort RT, Diepenbroek A, Gaillard CA. High fall incidence and fracture rate in elderly dialysis patients. Neth J Med. 2014;72:509-15.

8. Li M, Tomlinson G, Naglie G, Cook WL, Jassal SV. Geriatric comorbidities, such as falls, confer an independent mortality risk to elderly dialysis patients. Nephrol Dial Transplant. 2008;23:1396-400.

9. Shinzato T, Nakai S, Fujita Y, et al. Determination of Kt/V and protein catabolic rate using pre- and postdialysis blood urea nitrogen concentrations. Nephron. 1994;67:280-90.

10. McAdams-DeMarco MA, Suresh S, Law A, Salter ML, Gimenez LF, Jaar BG, et al. Frailty and falls among adult patients undergoing chronic hemodialysis: a prospective cohort study. BMC Nephrology. 2013;14:224.

11. Johansen KL, Shubert T, Doyle J, Soher B, Sakkas GK, Kent-Braun JA. Muscle atrophy in patients receiving hemodialysis: effects on muscle strength, muscle quality, and physical function. Kidney Int. 2003;63:291-7.

12. Janssen I, Heymsfield SB, Baumgartner RN, Ross R. Estimation of skeletal muscle mass by bioelectrical impedance analysis. J Appl Physiol. 2000;89:465-71.

13. Tillquist M, Kutsogiannis DJ, Wischmeyer PE, Kummerlen C, Leung R, Stollery D, et al. Bedside ultrasound is a practical and reliable measurement tool for assessing quadriceps muscle layer thickness. J Parenter Enteral Nutr. 2014;38:886-90.

14. Miyatani $M$, Kanehisa $H$, Ito $M$, Kawakami $Y$, Fukunaga $T$. The accuracy of volume estimates using ultrasound muscle thickness measurements in different muscle groups. Eur J Appl Physiol. 2004;91:264-72.

15. Sabatino A, Regolisti G, Bozzoli L, Fani F, Antoniotti R, Maggiore U, et al. Reliability of bedside ultrasound for measurement of quadriceps muscle thickness in critically ill patients with acute kidney injury. Clin Nutr. 2017;36:1710-5.

16. Watanabe T, Murakami H, Fukuoka D, Terabayashi N, Shin S, Yabumoto T, et al. Quantitative sonographic assessment of the quadriceps femoris muscle in healthy Japanese adults. J Ultrasound Med. 2017;36:1383-95.

17. Dupont AC, Sauerbrei EE, Fenton PV, Shragge PC, Loeb GE, Richmond FJ. Real-time sonography to estimate muscle thickness: comparison with MRI and CT. J Clin Ultrasoud. 2001;29:230-6.

18. Sabatino A, Regolisti G, Delsante M, Di Motta T, Cantarelli C, Pioli S, et al. Noninvasive evaluation of muscle mass by ultrasonography of quadriceps femoris muscle in end-stage renal disease patients on hemodialysis. Clin Nutr. 2019;38:1232-9.

19. Desmet C, Beguin C, Swine C, Jadoul M, Université Catholique de Louvain Collaborative Group. Falls in hemodialysis patients: prospective study of incidence, risk factor, and complications. Am J Kidney Dis. 2005;45:148-15.

20. Plantinga LC, Patzer RE, Franch HA, Bowling CB. Serious fall injuries before and after initiation of hemodialysis among older ESRD patients in the United States: A Retrospective Cohort Study. Am J 
Kidney Dis. 2017;70:76-83.

21. Schwartz AV, Hillier TA, Sellmeyer DE, Resnick HE, Gregg E, Ensrud KE, et al. Older women with diabetes have a higher risk of falls. Diabetes Care. 2002;25:1749-54.

22. Yau RK, Strotmeyer ES, Resnick HE, Sellmeyer DE, Feingold KR, Cauley JA, et al. Diabetes and risk of hospitalized fall injury among older adults. Diabetes Care. 2013;36:3985-91.

23. Meskers CGM, Reijnierse EM, Numans ST, Kruizinga RC, Pierik VD, van Ancum JM, et al. Association of handgrip strength and muscle mass with dependency in (instrumental) activities of daily living in hospitalized older adults -The EMPOWER Study. J Nutr Health Aging. 2019;23:232-8.

24. Lauretani F, Russo CR, Bandinelli S, Bartali B, Cavazzini C, Di lorio A, et al. Age-associated changes in skeletal muscles and their effect on mobility: an operational diagnosis of sarcopenia. J Appl Physiol. 2003;95:1851-60.

25. Goodpaster BH, Park SW, Harris TB, Kritchevsky SB, Nevitt M, Schwartz AV, et al. The loss of skeletal muscle strength, mass, and quality in older adults: The health, aging and body composition study. $J$ Gerontol A Biol Sci Med Sci. 2006;61:1059-64.

26. Rolland Y, Czerwinski S, Abellan Van Kan G, Morley JE, Cesari M, Onder G, et al. Sarcopenia: its assessment, etiology, pathogenesis, consequence and future perspectives. J Nutr Health Aging. 2008;12:433-50.

27. Landi F, Liperoti R, Russo A, Giovannini S, Tosato M, Capoluongo E, et al. Sarcopenia as a risk factor for falls in elderly individuals: results from the iISIRENTE study. Clin Nutr. 2012;31:652-8.

28. Isoyama N, Qureshi AR, Avesani CM, Lindholm B, Bàràny $P$, Heimbürger $\mathrm{O}$, et al. Comparative associations of muscle mass and muscle strength with mortality indialysis patients. Clin $\mathrm{J} \mathrm{Am} \mathrm{Soc}$ Nephrol. 2014;9:1720-8.

29. Johansson L, Fouque D, Bellizzi V, Chauveau P, Kolko A, Molina P, et al. European Renal Nutrition (ERN) Working Group of the European Renal Association-European Dialysis Transplant Association (ERA-EDTA). As we grow old: nutritional considerations for older patients on dialysis. Nephrol Dial Transplant. 2017;32:1127-36.

\section{Figures}




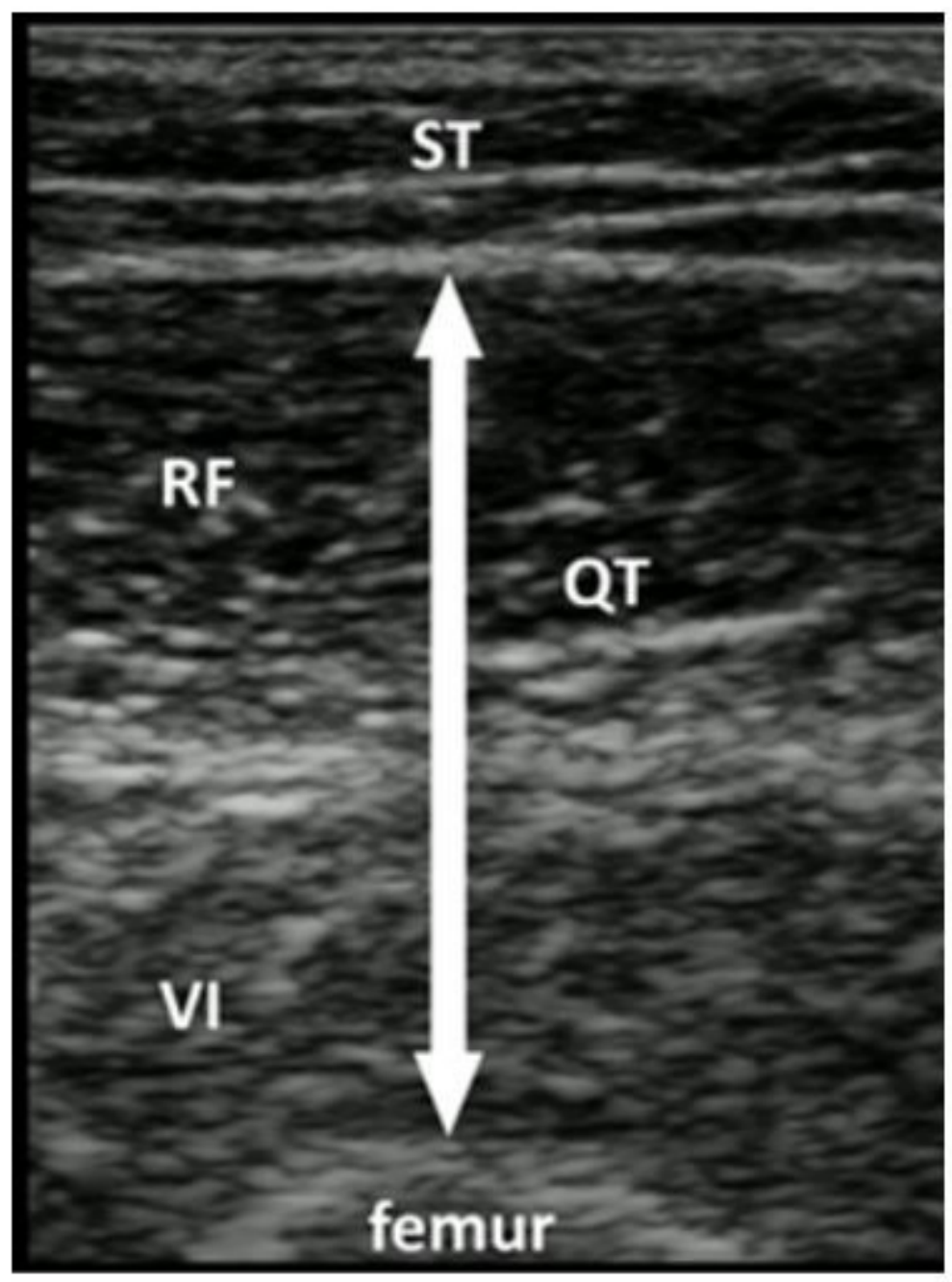

\section{Figure 1}

Ultrasonogram of the quadriceps muscle thickness Abbreviations: ST, subcutaneous tissue; RF, rectus femoris; VI, vastus intermedius muscle; QT, quadriceps muscle thickness The QT which consists of the rectus femoris and the vastus intermedius muscle was measured in the axial view at the midpoint between the anterior superior iliac spine and the lateral epicondyle of the femur. Using a B-mode ultrasound apparatus (LOGIQ BOOK XP; GE Healthcare Japan, Tokyo, Japan) with a linear scanner, the procedure was conducted by a single examiner to patients in supine position after dialysis. 
Men

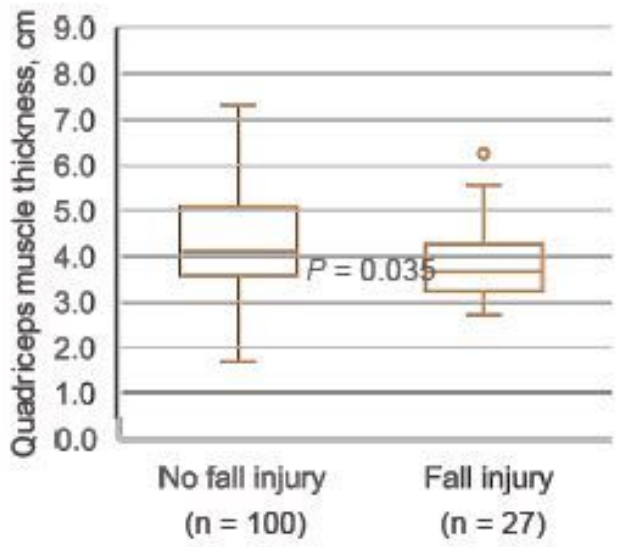

Median, $4.1 \quad$ Median, 3.7

IQR, 3.6-5.1 IQR, 3.3-4.3

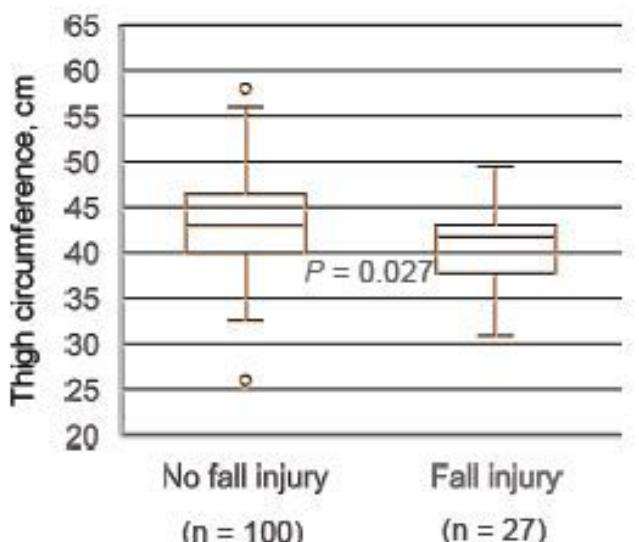

Median, 43 Median, 42

IQR, 40-47 IQR, 39-43

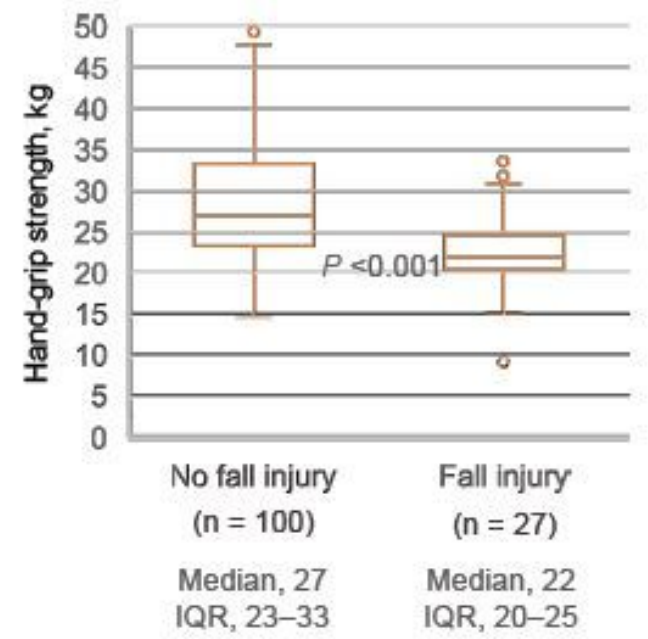

Women

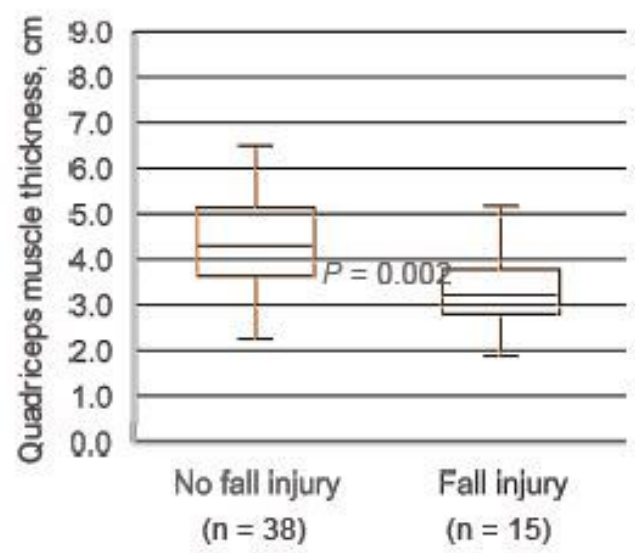

Median, 4.3 Median, 3.2

IQR, 3.6-5.1 IQR, 2.8-3.8

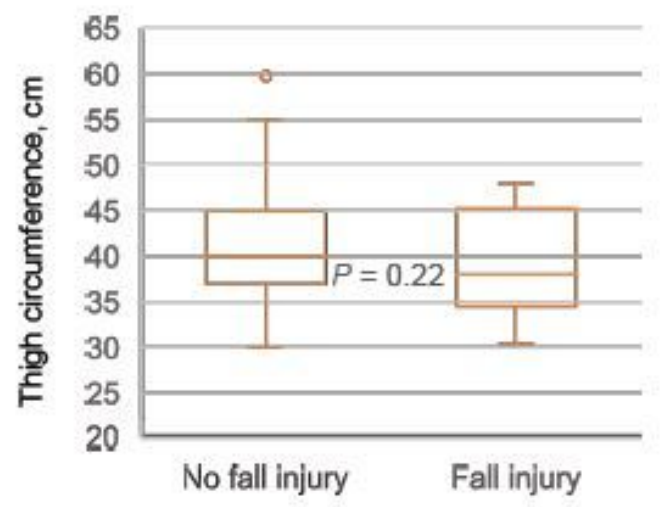

$(n=38) \quad(n=15)$

Median, $40 \quad$ Median, 38

IQR, 37-45 IQR, 35-46

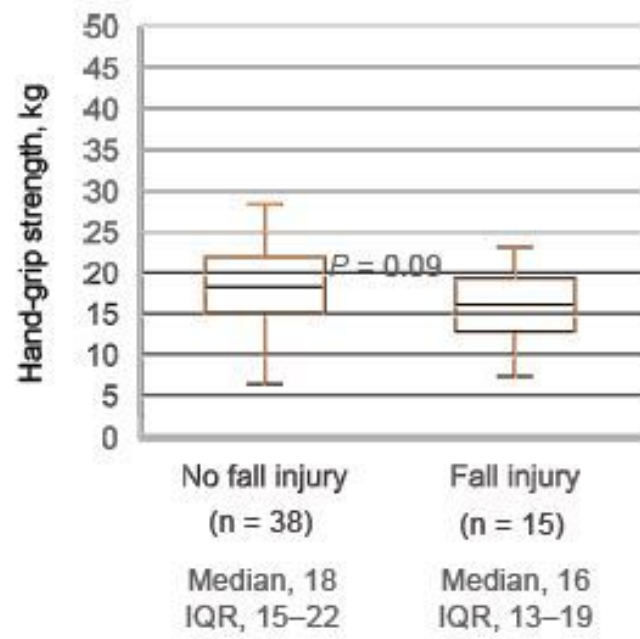

\section{Figure 2}

Box plots depicting the associations of fall injury with quadriceps muscle thickness, thigh circumference, and handgrip strength 


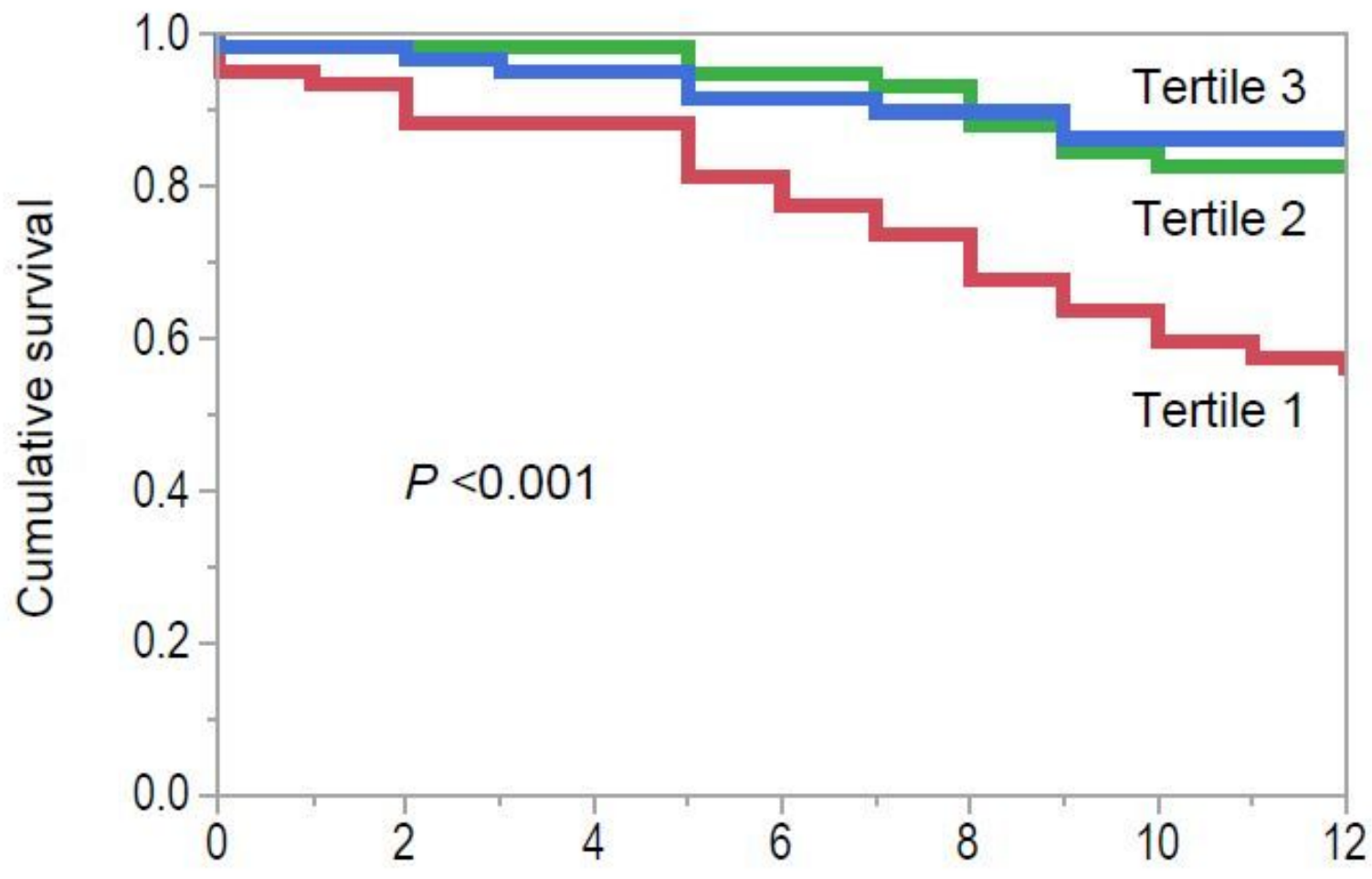

Number of risk

$\begin{array}{lllllllllllll}\text { - Tertile } 1 & 57 & 56 & 52 & 51 & 50 & 43 & 40 & 37 & 34 & 31 & 27 & 26\end{array}$

$\begin{array}{lllllllllllll}- \text { Tertile } 2 & 60 & 59 & 59 & 58 & 57 & 57 & 55 & 54 & 50 & 47 & 46 & 44\end{array}$

$\begin{array}{lllllllllllll}- \text { Tertile } 3 & 60 & 59 & 57 & 56 & 55 & 53 & 52 & 52 & 51 & 51 & 49 & 48\end{array}$

Figure 3

Kaplan-Meier curves for fall injury by tertiles of quadriceps muscle thickness 